\title{
Effect of Late-Onset Sepsis on Energy Expenditure in Extremely Premature Infants
}

\author{
ILANA J. TORINE, SCOTT C. DENNE, SHIRLEY WRIGHT-COLTART, AND CATHERINE LEITCH
}

Department of Pediatrics, Section of Neonatal-Perinatal Medicine, Indiana University School of Medicine, Indianapolis, Indiana 46202

\begin{abstract}
The purpose of this study was to compare total energy expenditure (TEE) in extremely premature infants during and after an episode of sepsis. We hypothesized that TEE in the sepsis group (SEP) would be higher during the septic period and higher than an age-matched control group (CTL). We further hypothesized that the TEE of the SEP group during the recovery period would be similar to that of the CTL group. The doubly labeled water method was used to determine TEE in both groups. Infant characteristics were as follows: SEP group, $n=10$, gestation $=26 \pm 1 \mathrm{wk}$, birth weight $=$ $854 \pm 218 \mathrm{~g}$; CTL group, $n=10$, gestation $=26 \pm 1 \mathrm{wk}$, birth weight $=880 \pm 158 \mathrm{~g}$. TEE of the SEP group during the septic period was significantly greater than during the recovery period (96 $\pm 25 \mathrm{kcal} / \mathrm{kg} / \mathrm{d}$ versus $55 \pm 17 \mathrm{kcal} / \mathrm{kg} / \mathrm{d}$ ) and significantly greater than the CTL group during the first study period $(96 \pm 25 \mathrm{kcal} / \mathrm{kg} / \mathrm{d}$ versus $67 \pm 12 \mathrm{kcal} / \mathrm{kg} / \mathrm{d}$ ). TEE in the SEP group during the recovery period was similar to the CTL group. These increases in TEE may contribute to impaired growth and need to be considered when providing nutritional support for extremely premature infants. (Pediatr Res 61: 600-603, 2007)
\end{abstract}

$I^{n}$ nfections remain a common and important problem in premature infants. Late-onset sepsis ( $>72 \mathrm{~h}$ of life) occurs in approximately $20 \%$ of very low birth weight infants and $35 \%$ of extremely low birth weight infants (1). Morbidities in survivors of late-onset sepsis are significant and include neurodevelopmental disabilities and poor growth outcomes (2). Understanding how particular clinical conditions in extremely premature infants $(<29$ wk of gestation) affect nutritional requirements is necessary to support optimal growth. Specifically, the effect of late-onset sepsis on energy expenditure and requirements has not been evaluated in extremely preterm infants. Studies in adult subjects with sepsis have documented 50\%-90\% higher energy expenditures (3-5); a 20\% increase in energy expenditure has been measured in full-term neonates with early-onset sepsis (6).

The purpose of this study was to measure TEE in extremely premature infants during an episode of late-onset sepsis and again after recovery using the doubly labeled water technique. To control for the potential effect of time, TEE was also

Received October 5, 2006; accepted January 4, 2007.

Correspondence: Scott C. Denne, M.D., Indiana University School of Medicine, Department of Pediatrics, Riley Hospital for Children, 699 West Drive, RR 208, Indianapolis, IN 46202; e-mail: sdenne@iupui.edu

This work was supported by grants from the James Whitcomb Riley Memorial Association and the National Institutes of Health (S10-RR-07269, M01-RR-750, R01HD-29153).

DOI: $10.1203 /$ pdr.0b013e3180459f9d measured in a control group of age- and gestation-matched extremely preterm infants without sepsis. We hypothesized that TEE would be higher in the septic group during the septic episode compared with recovery. We further hypothesized that TEE would be higher in the septic group during sepsis compared with the control group.

\section{METHODS}

Subjects. The study population consisted of two groups. The first included 10 infants with sepsis (SEP group) documented by a positive blood culture. The second was the CTL group of 10 infants without sepsis. Infants were eligible for inclusion in the study at $>72 \mathrm{~h}$ of life with birth weights $<1500$ $\mathrm{g}$ and gestational ages $<29 \mathrm{wk}$. Exclusion criteria included any chromosomal and/or congenital anomalies, seizures, or necrotizing enterocolitis. Variance expressed as mean \pm standard deviation (SD). Patient characteristics at birth for the SEP group were a mean gestational age of $26 \pm 1 \mathrm{wk}$, mean birth weight of $854 \pm 218 \mathrm{~g}$, mean length of $34 \pm 3 \mathrm{~cm}$, and a mean occipitofrontal circumference of $24 \pm 2 \mathrm{~cm}$. Patient characteristics for the CTL group were a mean gestational age of $26 \pm 1 \mathrm{wk}$, mean birth weight of $880 \pm 158 \mathrm{~g}$, mean length of $34 \pm 2 \mathrm{~cm}$, and a mean occipitofrontal circumference of $23 \pm 1 \mathrm{~cm}$. The CTL group was matched to the SEP group for gestational age, weight, and chronological age. This study was approved by the Institutional Review Board of Indiana University-Purdue University at Indianapolis, and informed consent was obtained from the infants' parents or legal guardians before initiation of the study.

Study timeline. TEE was determined for each group during two study periods of $7 \mathrm{~d}$. For the SEP infants, the first study period occurred during the septic episode, while the infants were being treated with antibiotics; the second study period was after sepsis had resolved and infants were no longer receiving antibiotics. The time between study periods was at least $7 \mathrm{~d}$ with a mean of $11 \pm 5 \mathrm{~d}$ (range, 7-21 d). Energy expenditure was also measured in the CTL group during two study periods when the infants were age-matched to the SEP group.

Energy expenditure. The doubly labeled water method $(7,8)$ was used to calculate TEE in both groups. This method is a noninvasive technique using stable isotopes of deuterium $\left({ }^{2} \mathrm{H}\right)$ and ${ }^{18} \mathrm{O}$ to measure TEE over time in free-living individuals. Deuterium is eliminated from the body as labeled water, whereas ${ }^{18} \mathrm{O}$ is eliminated from the body as labeled water and $\mathrm{CO}_{2}$. If both the oxygen and hydrogen elimination rates are known, the $\mathrm{CO}_{2}$ production rate can be determined. Total body water (TBW) was determined from the dilution of the isotopes in the body water pool. Once the TBW is known, TEE can then be calculated from the TBW measurement, the $\mathrm{CO}_{2}$ production rate, and the respiratory or food quotient.

After collection of a baseline urine sample, ${ }^{2} \mathrm{H}$ - and ${ }^{18} \mathrm{O}$-labeled water $[2.0$ $\mathrm{g}$ of $\mathrm{H}_{2}{ }^{18} \mathrm{O} / \mathrm{kg}, 10.0$ atom \% excess (Cambridge Isotope Laboratories, Inc., Andover, MA) and $0.08 \mathrm{~g}$ of ${ }^{2} \mathrm{H}_{2} \mathrm{O} / \mathrm{kg}, 99.8$ atom \% excess (Isotec, Inc., Miamisburg, $\mathrm{OH})]$ was administered via orogastric tube. Sequential urine samples were collected for the next $24 \mathrm{~h}$ for determination of the TBW pool size. Daily urine samples were then collected for $7 \mathrm{~d}$ for determination of the isotope elimination rates. On the last day of each study period, an additional dose of doubly labeled water was administered $\left(1.0 \mathrm{~g}\right.$ of $\mathrm{H}_{2}{ }^{18} \mathrm{O}$ and $0.04 \mathrm{~g}$ of ${ }^{2} \mathrm{H}_{2} \mathrm{O} / \mathrm{kg}$ ) and serial urine samples were collected over $24 \mathrm{~h}$ to assess any changes in TBW over the study period. All urine samples were obtained from cotton balls placed in the infant's diaper and the dates and times of collection

Abbreviations: CTL, control; SEP, sepsis; TBW, total body water; TEE, total energy expenditure 
were recorded. Samples were prepared using standard vacuum techniques and analyzed using isotope ratio mass spectrometry (Finnigan MAT 252, San Jose, CA).

Energy intake. Weights and caloric intakes (enteral and parenteral) were recorded daily. Clinical status and medications were also recorded throughout the study periods.

Calculations. Isotope dilution spaces were calculated from the amount of isotope administered and the baseline and peak concentrations of the isotopes in the urine, according to the formula: $\mathrm{DS}=\left(\mathrm{A} \times \mathrm{W} \times \mathrm{E}_{\mathrm{a}}\right) /\left(\mathrm{a} \times \mathrm{E}_{\mathrm{d}} \times 10^{3}\right)$, where DS $(\mathrm{kg})$ is the body dilution space, $\mathrm{A}(\mathrm{g})$ is the dose administered to the subject, W (g) is the amount of laboratory water used to dilute the dose for analysis, $\mathrm{E}_{\mathrm{a}}$ is the change in the isotopic enrichment of the laboratory water after addition of the dose, a $(\mathrm{g})$ is the amount of the dose added to the laboratory water in the dose dilution, $\mathrm{E}_{\mathrm{d}}$ is the change in enrichment of the body water pool after the administration of the dose.

TBW was calculated from the dilution spaces of both deuterium and ${ }^{18} \mathrm{O}$ (9). Because the body dilution spaces of oxygen and hydrogen are not identical, TBW $(\mathrm{kg})$ is defined as DS divided by 1.01 and 1.04 , respectively. No difference in TBW pool size was found between isotopes, and the mean values were used in further calculations. No difference in TBW pool size (expressed as \% body weight) was found between the beginning and end of the study period. However, because the infants were growing over the 7-d study periods, the mean TBW pool size was determined from the following equation (10): TBW $(\mathrm{kg})=\left(\mathrm{TBW}_{1}-\mathrm{TBW}_{2}\right) / \mathrm{ln}\left(\mathrm{TBW}_{1} / \mathrm{TBW}_{2}\right)$, where $\mathrm{TBW}_{1}$ is the initial TBW and $\mathrm{TBW}_{2}$ is the final TBW expressed in kilograms. In cases where the difference in initial and final TBW is small, this value is nearly identical to the average of the initial and final values.

The isotope elimination rates were calculated from the decline in isotope enrichments over the study period. The rate of $\mathrm{CO}_{2}$ production $\left(\mathrm{rCO}_{2}\right)$ in mole/d was then calculated by the following equation $(7,8): \mathrm{rCO}_{2}=0.445 \times$ TBW $\times\left(1.01 \mathrm{k}_{18}-1.04 \mathrm{k}_{2}\right)$, where 0.445 is a factor that incorporates the fractionation of deuterium in water vapor, ${ }^{18} \mathrm{O}$ in water vapor, ${ }^{18} \mathrm{O}$ in carbon dioxide, and an estimation of transcutaneous water losses, as described by Jones et al. (7); TBW is in kilograms and $\mathrm{k}_{18}$ and $\mathrm{k}_{2}$ are the calculated elimination rates of ${ }^{18} \mathrm{O}$ and deuterium, respectively. The $\mathrm{rCO}_{2}$ is then converted to daily TEE in $\mathrm{kcal} / \mathrm{d}$ using the Weir equation (11): TEE $=22.4$ $\times\left(1.10 \mathrm{rCO}_{2}+3.94 \mathrm{rO}_{2}\right)-2.17 \times \mathrm{U}_{\mathrm{N}}$, where $\mathrm{rO}_{2}$ is calculated from the respiratory quotient (RQ) or food quotient $(\mathrm{FQ})$ of the diet, and $\mathrm{U}_{\mathrm{N}}$ is the 24-h urinary nitrogen excretion in grams. In practice, the contribution from the last term is minor and can be ignored. An RQ of 0.91 was used in the calculations, as suggested for infants in this age group (12-14). Alternatively, FQs could be used for calculation. FQs were determined for all infants during each study period. The FQ did not differ between groups or during study periods (SEP period 1: $0.86 \pm 0.04$, period 2: $0.86 \pm 0.02$; CTL period 1: $0.86 \pm$ 0.02 , period 2: $0.85 \pm 0.02$ ). Using FQ rather than RQ would increase all energy expenditure values by $5 \%$, but would not change the conclusions of this study.

Statistics. Results were compared using paired $t$ tests and analysis of variance. All results are expressed as mean $\pm \mathrm{SD}$.

\section{RESULTS}

Subjects. Table 1 shows infants' characteristics during both study periods. No statistically significant differences existed between groups in age or weight during the study periods. Diagnoses in the SEP group included coagulase-negative Staphylococcus $(n=6)$, Escherichia coli $(n=1)$, Enterococcus $(n=1)$, coagulase-negative Staphylococcus and Escherichia coli $(n=1)$, and coagulase-negative Staphylococcus and Enterococcus $(n=1)$. All infants in the SEP group had a documented positive blood culture. All infants in this group had mild to moderate respiratory distress syndrome during the

Table 1. Patient characteristics during study periods

\begin{tabular}{cccccc}
\hline & \multicolumn{2}{c}{ Period 1} & & \multicolumn{2}{c}{ Period 2} \\
\cline { 2 - 3 } \cline { 5 - 6 } Group & Age, d & Weight, g & & Age, d & Weight, g \\
\hline SEP, $n=10$ & $14 \pm 6$ & $908 \pm 250$ & & $35 \pm 11$ & $1319 \pm 439$ \\
CTL, $n=10$ & $20 \pm 7$ & $1030 \pm 333$ & & $36 \pm 7$ & $1337 \pm 413$ \\
\hline
\end{tabular}

All values are mean \pm SD. septic period (period 1), and all required mechanical ventilation (ventilator rate $35 \pm 9$, PIP $15 \pm 3$, PEEP $5 \pm 1$, $\mathrm{Fio}_{2}$ $0.35 \pm 0.09$ ). All infants in the CTL group during period 1 also had mild to moderate respiratory distress syndrome: five required continuous positive airway pressure or nasal cannula oxygen, and five required mechanical ventilation at ventilator settings similar to the those in the SEP group (ventilator rate $31 \pm 9$, PIP $16 \pm 5$, PEEP $5 \pm 1, \mathrm{Fio}_{2} 0.38 \pm 0.10$ ). During period 2, four infants in the SEP group and one infant in the CTL group required mechanical ventilation at settings similar to those in period 1 . The remainder of the infants in both the SEP and CTL groups during period 2 required continuous positive airway pressure or nasal cannula oxygen, with the exception of one infant in the CTL group in room air. All infants in both groups were in servo-controlled isolettes to maintain a skin temperature of $36.5^{\circ} \mathrm{C}$ during the study periods.

Energy expenditure. The results of TEE are summarized in Table 2. Figure 1 shows the TEE results for the SEP group during the septic episode (period 1) and after sepsis had been resolved (period 2); Figure 2 shows the results of TEE of all infants in the CTL group during both study periods. The mean TEE in the SEP group during the septic period was $96 \pm 25$ $\mathrm{kcal} / \mathrm{kg} / \mathrm{d}$ compared with $55 \pm 17 \mathrm{kcal} / \mathrm{kg} / \mathrm{d}$ during recovery. The mean TEE was nearly double during sepsis compared with the recovery period $(p \leq 0.002)$. All infants showed a decrease in TEE during recovery from sepsis, although two infants showed small decreases in TEE of $3 \mathrm{kcal} / \mathrm{kg} / \mathrm{d}$ and 10 $\mathrm{kcal} / \mathrm{kg} / \mathrm{d}$. The mean TEE in the CTL group during period 1 was $67 \pm 12 \mathrm{kcal} / \mathrm{kg} / \mathrm{d}$ compared with $69 \pm 17 \mathrm{kcal} / \mathrm{kg} / \mathrm{d}$ during period 2 . These were not significantly different. In comparing the two groups, the TEE of the SEP group during the septic episode was significantly greater $(p \leq 0.02)$ than that of the age-matched CTL group. Energy expenditure in the SEP group during the recovery period was lower than in the CTL group, but this difference did not reach statistical significance.

Energy intake. The results of energy intake are summarized in Table 2. Energy intakes were obtained for all infants from medical records. During the septic period, the SEP infants received a combination of parenteral nutrition and orogastric feedings ( $62 \pm 19 \%$ parenteral nutrition); during the recovery period, all infants received orogastric feedings. Four of the CTL infants during period 1 received parenteral nutrition and orogastric feedings ( $48 \pm 25 \%$ parenteral nutrition); the remainder of the CTL group received orogastric feedings only. All CTL infants received orogastric feedings during period 2. The mean energy intake for the SEP group during period 1 was $106 \pm 12 \mathrm{kcal} / \mathrm{kg} / \mathrm{d}$ and $120 \pm 12 \mathrm{kcal} / \mathrm{kg} / \mathrm{d}$ during period 2. Energy intake was significantly lower in these infants during the septic period compared with the recovery period $(p \leq 0.002)$. The energy intakes for the control group were $116 \pm 11 \mathrm{kcal} / \mathrm{kg} / \mathrm{d}$ and $117 \pm 15 \mathrm{kcal} / \mathrm{kg} / \mathrm{d}$ for periods 1 and 2 , respectively. There was no statistically significant difference in energy intake in this group.

Energy balance. The results of energy balance as estimated by energy intake minus energy expenditure are summarized in Table 2 . The septic infants were in modestly positive energy balance during period $1(9 \pm 24 \mathrm{kcal} / \mathrm{kg} / \mathrm{d}$, seven of 10 subjects in positive balance) and in strongly positive energy 
Table 2. Summary of energy expenditure, energy intake, and energy balance

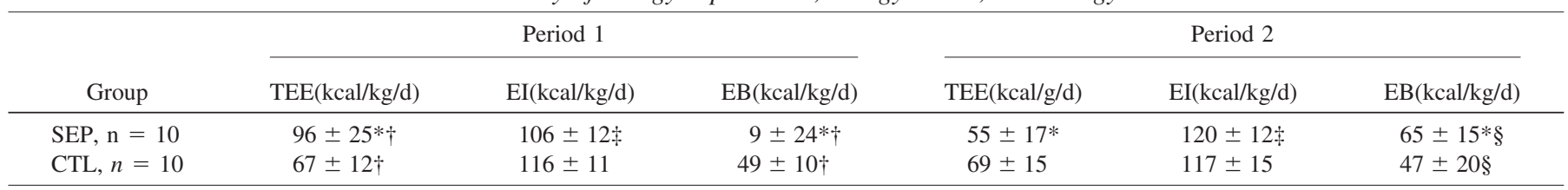

EI, energy intake; EB, energy balance.

$* p \leq 0.005$ (SEP group, period $1 v s$ period 2).

$\dagger p \leq 0.005$ (SEP group, period 1 vs CTL group period 1).

$\ddagger p \leq 0.005$ (SEP group, period 1 vs period 2).

$\S p \leq 0.05$ (SEP group, period $2 v s$ CTL group, period 2).

balance during period $2(65 \pm 15 \mathrm{kcal} / \mathrm{kg} / \mathrm{d}$, all subjects positive, $p \leq 0.001)$. All control infants were in positive energy balance throughout the entire study (period 1: $49 \pm 10$ $\mathrm{kcal} / \mathrm{kg} / \mathrm{d}$; period 2: $47 \pm 20 \mathrm{kcal} / \mathrm{kg} / \mathrm{d}$ ).

$\boldsymbol{T B W}$. The mean $\% \mathrm{TBW}$ for the SEP infants during period 1 was $81 \pm 7 \%$ and during period 2 it was $76 \pm 5 \%$ ( $p \leq$ 0.05). The mean $\%$ TBW for the CTL infants during period 1 was $79 \pm 6 \%$ and during period 2 it was $78 \pm 6 \%$. There were no statistically significant differences in the $\%$ TBW between groups.

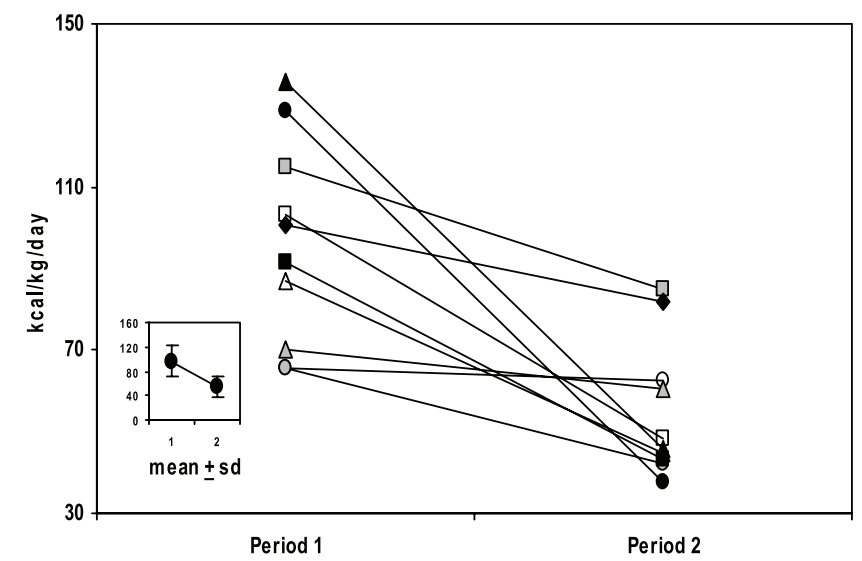

Figure 1. Energy expenditure in the SEP group. The TEE of individual infants in the SEP group during each study period. The inset represents mean \pm SD of all infants in the SEP group during each study period.

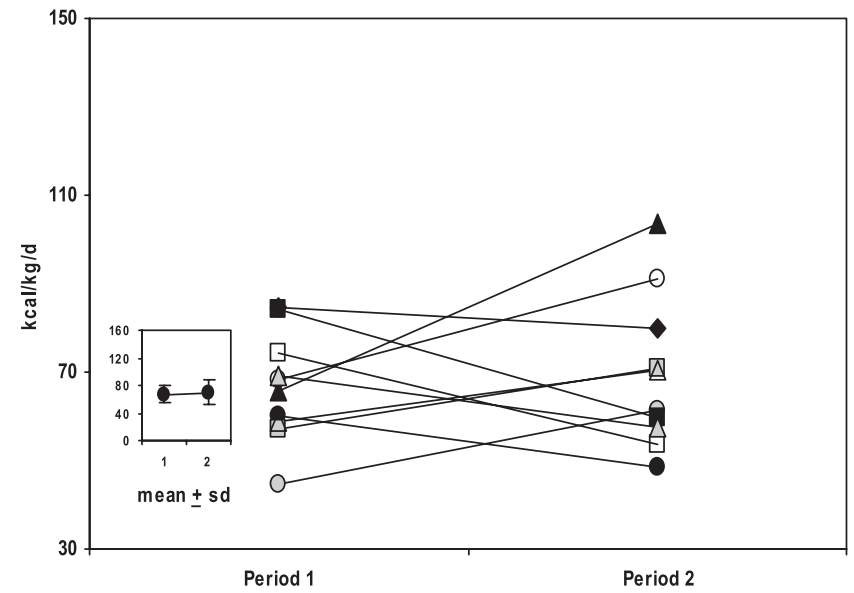

Figure 2. Energy expenditure in the CTL group. The TEE of individual infants in the CTL group during each study period. The inset represents mean \pm SD of all infants in the CTL group during each study period.
Weight gain. The weight gain for septic infants during period 1 was similar to the weight gain for these same infants during period $2(16.6 \pm 6.7 \mathrm{~g} / \mathrm{d}$ versus $19.2 \pm 14.2 \mathrm{~g} / \mathrm{d})$. There were no differences in weight gain for the control infants during the two study periods $(18.5 \pm 12.7 \mathrm{~g} / \mathrm{d}$ versus $14.4 \pm 23.3 \mathrm{~g} / \mathrm{d})$.

\section{DISCUSSION}

In the present study, TEE was measured in extremely premature infants during a culture-positive septic episode and again during recovery. TEE during sepsis was approximately $70 \%$ higher compared with recovery, and TEE was higher during sepsis in each individual subject. TEE during sepsis was also approximately $40 \%$ higher compared with an age- and gestationmatched control group. After recovery, TEE in infants who experienced sepsis was similar to that in control infants.

The present study used the doubly labeled water technique to determine energy expenditure without altering the clinical environment. Energy expenditure was measured over $7 \mathrm{~d}$ reflecting the energy needs over a reasonable period, although the method does not assess day-to-day changes in energy expenditure. The doubly labeled water method has been used successfully in difficult-to-study populations, including preterm infants with chronic lung disease on and off steroids (13). The method has been extensively validated, including in healthy term infants, infants recovering from surgery, and preterm infants $(7,14-18)$; however, the method may be better suited for the estimation of TEE of groups rather than individuals $(15,19)$. Potential errors can be produced by fractionation of isotope via insensible water loss as well as reentry of isotopic label, but the effect of these factors on TEE estimates are relatively small (3\%-4\%) and occur in opposite directions. In the present study, both control and septic infants shared the same clinical characteristics (except sepsis) and were studied in the same environment, so both groups experienced any errors of the method. In addition, TEE estimates of the control group are consistent with measurements made by respiratory calorimetry in subjects of similar gestational and postnatal age $(20,21)$. It therefore seems likely that the determinations made in the present study reasonably reflect energy expenditure during sepsis in extremely preterm infants.

The present study is limited by a relatively small sample size - 10 subjects each in the SEP and CTL groups. However, despite the small sample size, consistent elevations of TEE were observed during sepsis in the SEP group and in comparison with the CTL group, lending credibility to the findings. 
The characteristics of the 10 septic extremely premature infants studied are similar to those observed in large population studies, both in the age of acquisition of late-onset sepsis and in the predominance of Gram-positive organisms (coagulasenegative Staphylococcus, in particular) (1).

Sepsis in the extremely preterm infant of the present study resulted in a 40\%-70\% increase in TEE for the group, even with a predominance of coagulase-negative staphylococcal infections. The magnitude of this increase, although large, is similar to that observed in a number of studies of septic adults. Frankenfield et al. (5) determined that resting energy expenditure was $90 \%$ greater than the predicted basal energy expenditure in adults with sepsis and organ dysfunction. Koea and coworkers (4) showed a $40 \%$ increase in resting energy expenditure and a 50\% increase in TEE in septic compared with nonseptic patients; similar results have been obtained in septic patients with peritonitis (3). In a recent study of normal term newborns with early-onset sepsis, Bauer et al. (6) determined that resting energy expenditure was increased by $20 \%$ for the first $3 \mathrm{~d}$ and $15 \%$ at $\mathrm{d} 4$ compared with control infants. It is important to point out that these term infants with sepsis were mildly ill and did not require supplemental oxygen or mechanical ventilation. In addition, only six of 10 of the term infants had positive blood cultures. Nevertheless, the effect of sepsis to produce increases in energy expenditure in term infants is consistent with the findings of the present study.

The specific factors responsible for the increase in TEE during sepsis cannot be precisely delineated from the present study. However, it does not appear that respiratory status and the need for mechanical ventilation during sepsis was a primary factor. When energy expenditure measured in septic infants during the septic period (all on ventilators) was compared with the five control infants who required mechanical ventilation, the findings remain significant and the magnitude of the difference is unchanged $(96 \pm 25 \mathrm{kcal} / \mathrm{kg} / \mathrm{d}$ sepsis versus $69 \pm 11 \mathrm{kcal} / \mathrm{kg} / \mathrm{d}$ control, $p \leq 0.05$ ). There was also no relationship in the present study between the type of bacteria producing sepsis and TEE, although the number and variety of organisms is clearly limited. Sepsis-induced changes in cytokines are a more likely mechanism for the increase in TEE. Cytokines were not measured in the present study, but they are known to be increased in neonatal sepsis (22) and to be important modulators of energy metabolism $(23,24)$.

In summary, late-onset sepsis produced by typical organisms (including coagulase-negative Staphylococcus) in extremely preterm infants increases TEE by $40 \%-70 \%$; these elevations in TEE appear to be a quite consistent response to sepsis. Sepsis in extremely premature infants is documented to adversely effect growth outcomes (2), and significant increases in energy expenditure are likely to be an important contributor to this finding.

\section{REFERENCES}

1. Stoll BJ, Hansen N, Fanaroff AA, Wright LL, Carlo WA, Ehrenkranz RA, Lemons JA, Donovan EF, Stark AR, Tyson JE, Oh W, Bauer CR, Korones SB, Shankaran S, Laptook AR, Stevenson DK, Papile LA, Poole WK 2002 Late-onset sepsis in very low birth weight neonates: the experience of the NICHD Neonatal Research Network. Pediatrics 110:285-291

2. Stoll BJ, Hansen NI, Adams-Chapman I, Fanaroff AA, Hintz SR, Vohr B, Higgins RD 2004 Neurodevelopmental and growth impairment among extremely low-birthweight infants with neonatal infection. JAMA 292:2357-2365

3. Plank LD, Connolly AB, Hill GL 1998 Sequential changes in the metabolic response in severely septic patients during the first 23 days after the onset of peritonitis. Ann Surg 228:146-158

4. Koea JB, Wolfe RR, Shaw JH 1995 Total energy expenditure during total parenteral nutrition: ambulatory patients at home versus patients with sepsis in surgical intensive care. Surgery 118:54-62

5. Frankenfield DC, Wiles CE 3rd, Bagley S, Siegel JH 1994 Relationships between resting and total energy expenditure in injured and septic patients. Crit Care Med 22:1796-1804

6. Bauer J, Hentschel R, Linderkamp O 2002 Effect of sepsis syndrome on neonatal oxygen consumption and energy expenditure. Pediatrics 110:e69-

7. Jones PJ, Winthrop AL, Schoeller DA, Swyer PR, Smith J, Filler RM, Heim T 1987 Validation of doubly labeled water for assessing energy expenditure in infants. Pediatr Res 21:242-246

8. Schoeller DA, Ravussin E, Schulz Y, Acheson KJ, Baertschi P, Jequier E 1986 Energy expenditure by doubly labeled water: validation and proposed calculation. Am J Physiol 250:R823-R830

9. Schoeller DA, van Santen E, Peterson DW, Dietz W, Jaspan J, Klein PD 1980 Total body water measurement in humans with $18 \mathrm{O}$ and $2 \mathrm{H}$ labeled water. Am J Clin Nutr 33:2686-2693

10. Butte NF, Wong WW, Garza C 1992 Prediction equations for total body water during early infancy. Acta Paediatr 81:264-265

11. Weir JB 1949 New methods for calculating metabolic rate with special reference to protein metabolism. J Physiol 109:1-9

12. Roberts SB, Coward WA, Schlingenseipen KH, Nohria V, Lucas A 1986 Comparison of the doubly labeled water $(2 \mathrm{H} 218 \mathrm{O})$ method with indirect calorimetry and a nutrient-balance study for simultaneous determination of energy expenditure, water intake, and metabolizable energy intake in preterm infants. Am J Clin Nutr 44:315-322

13. Leitch CA, Ahlrichs J, Karn C, Denne SC 1999 Energy expenditure and energy intake during dexamethasone therapy for chronic lung disease. Pediatr Res 46:109-113

14. Westerterp KR, Lafeber HN, Sulkers EJ, Sauer PJ 1991 Comparison of short term indirect calorimetry and doubly labeled water method for the assessment of energy expenditure in preterm infants. Biol Neonate 60:75-82

15. Jensen CL, Butte NF, Wong WW, Moon JK 1992 Determining energy expenditure in preterm infants: comparison of $2 \mathrm{H} 218 \mathrm{O}$ method and indirect calorimetry. Am J Physiol 263:R685-R692

16. Roberts SB, Coward WA, Schlingenseipen KH, Nohria V, Lucas A 1986 Comparison of the doubly labeled water $(2 \mathrm{H} 2(18) \mathrm{O})$ method with indirect calorimetry and a nutrient-balance study for simultaneous determination of energy expenditure, water intake, and metabolizable energy intake in preterm infants. Am J Clin Nutr 44:315-322

17. Roberts SB, Coward WA, Ewing G, Savage J, Cole TJ, Lucas A 1988 Effect of weaning on accuracy of doubly labeled water method in infants. Am J Physiol 254:R622-R627

18. Jones PJ, Winthrop AL, Schoeller DA, Filler RM, Swyer PR, Smith J, Heim T 1988 Evaluation of doubly labeled water for measuring energy expenditure during changing nutrition. Am J Clin Nutr 47:799-804

19. Speakman JR 1998 The history and theory of the doubly labeled water technique. Am J Clin Nutr 68:932S-938S

20. Bauer K, Laurenz M, Ketteler J, Versmold H 2003 Longitudinal study of energy expenditure in preterm neonates $<30$ weeks gestation during the first three postnatal weeks. J Pediatr 142:390-396

21. Bauer J, Maier K, Hellstern G, Linderkamp O 2003 Longitudinal evaluation of energy expenditure in preterm infants with birth weight less than 100 grams. $\mathrm{Br} \mathrm{J}$ Nutr 89:533-537

22. Ng PC, Li K, Wong RP, Chui K, Wong E, Li G, Fok TF 2003 Proinflammatory and anti-inflammatory cytokine responses in preterm infants with systemic infections. Arch Dis Child Fetal Neonatal Ed 88:F209-F213

23. Roubenoff R, Roubenoff RA, Cannon JG, Kehayias JJ, Zhuang H, Dawson-Hughes B, Dinarello CA, Rosenberg IH 1994 Rheumatoid cachexia: cytokine-driven hypermetabolism accompanying reduced body cell mass in chronic inflammation. J Clin Invest 93:2379-2386

24. Roubenoff R, Grinspoon S, Skolnik PR, Tchetgen E, Abad L, Spiegelman D, Knox T, Gorbach S 2002 Role of cytokines and testosterone in regulating lean body mass and resting energy expenditure in HIV-infected men. Am J Physiol Endocrinol Metab 283:E138-E145 